da tại khoa khám bệnh, Bệnh viện da liễu Thành phố Cần Thơ với tỉ lệ khách hàng đồng ý dịch vụ có chất lượng chung là $81,1 \%$, điểm trung bình chung chất lượng dịch vụ là 4,25(SD = $\pm 0,72)^{(5)}$.

\section{KẾT LUÂNN}

Kết quả nghiên cứu trên 280 người bệnh cho thấy tỉ lệ hài lòng chung đối với dịch vụ $\mathrm{C} Đ H A$ là $67,14 \%$. Tất cả các yếu tố của sự hài lòng đều đạt tỉ lệ dưới $80 \%$.

- Yểu tố "tin cậy" đạt tỉ lệ 75,36\%

- Yếu tố "đáp ứng" đat tỉ lệ $72,86 \%$

- Yễu tố "năng lực phục vư" đat 76,79\%

- Yếu tố "hữu hình" đạt tỉ lệ 74,64\%

- Yếu tố "đồng cảm" đạt tỉ lệ 73,93\%

\section{TÀI LIÊU THAM KHẢO}

1. Bô Y tế (2013), "Bô tiêu chí đánh giá chất lượng bệnh viện", Quyết định số 4858/QĐ-BYT, ngày 03 tháng 12 năm 2013 của Bộ trưởng Bộ Y tế.

2. Nguyễn Minh Quân (2020). "Thực trang và hiệu quả mô hình can thiệp nâng cao chất lượng khám chữa bệnh tại Bệnh viện quận Thủ Đức"', Luận văn Tiến sĩ Y học, Trường Đại Học Y Dược Huế

3. Hoàng Ngọc Quyên. (2020). "Chất lượing dịch vụ khám bệnh tại trung tâm Chẩn đoán hình ảnh, bệnh viện Hữu Nghị Việt Đức". Luận văn thạc sĩ quản trị kinh doanh. Học viện Khoa hộc và Xã hội.

4. Vương Quan Thành (2016). "Sự hài lòng của người bệnh về dịch vụ khám bệnh ngoại trú tại khoa khám bệnh và giải pháp cải thiện tại bệnh viện Quân Dân Y Đồng Tháp". Luận văn Chuyên Khoa II Tổ Chức Quản Lý Y Tế, Trường Đại Học Y Tế Công Cộng.

5. Nguyễn Văn Thắm (2018). Chất lượng dịch vụ chăm sóc da tại khoa khám - Bênh viên Da liễu Thành phố Cần Thơ và một số yểu tố ảnh hưởng năm 2018. Hà Nội: Trường Đại học $Y$ tế công cộng; 2018

6. Nguyê̂n Quốc Viêt (2016). "Đánh giá sư hài lòng của người bệnh và một số giải pháp cải thiện dich vu khám bênh tai khoa khám bệnh, bệnh viển Chỉnh Hình Và Phục Hồi Chức Năng Thành Phố Hî̀ Chí Minh". Luận vằn Chuyên Khoa II Tổ Chức Quản Lý Y Tế, Trường Đại Học Y Tế Công Cộng.

7. Parasuraman A, Valarie A. Zeithaml, Leonard L. Berry. (1985). "A Conceptual Model of Service Quality and Its Implications for Future Research". Journal of Marketing, 49(4): 41-50.

8. Wahed, Wafaa \& Mabrook, Shaimaa \& Abdel Wahed, Wafaa. (2017). "Assessment of patient satisfaction at Radiological Department of Fayoum University Hospitals". International Journal of Medicine in Developing Countries, 1(3): 126-131.

\title{
RỐI LOẠN CHỨC NĂNG TÂM TRƯƠNG THẤT TRÁI Ở BẾNH NHÂN XƠ' GAN DO VIRUS VIÊM GAN B
}

\section{TÓM TẮT}

Mục tiêu: Nghiên cứu chức năng tâm trương thất trái trên siêu âm tim ở bênh nhân (BN) xơ gan do virus viêm gan $B$ (HBV). Đối tượng và phương pháp: Nghiên cứu mô tả, cắt ngang trên $68 \mathrm{BN}$ xơ gan do HBV Child - Pugh B, C và 30 người nhóm chứng tai Trung tâm Bênh nhiêt đới và Viên Tim mach Bệnh viện Bạch Mai từ tháng 7/2020 đến tháng 8/2021. Các thông số nghiên cứu (NC) trên siêu âm tim: vận tốc $e^{\prime}$ vòng van hai lá ( $e^{\prime}$ vách, $e^{\prime}$ bên), tỷ lệ $\mathrm{E} / \mathrm{e}^{\prime}$ trung bình $\left(\mathrm{E} / \mathrm{e}^{\prime} \mathrm{TB}\right)$, chỉ số thể tích nhĩ trái tối đả (LAVi $\mathrm{ml} / \mathrm{m}^{2}$ ), và vận tốc tối đa dòng hở van ba lá (TRV m/s). Kết luận: Vận tốc e' vách, e' bên giảm, tỷ lệ E/e'TB tăng, TRV tăng, LAVi tăng ở nhóm xơ gan do HBV khi so sánh với nhóm chứng, $\mathrm{p}<0.01 ; 48.5 \% \mathrm{BN}$ xơ gan do HBV có rối loạn CNTTr thất trái. Mức độ

${ }^{1}$ Trường Đai hoc y Hà Nọi

${ }^{2}$ Viện tim mạch Việt Nam, Bệnh viện Bạch Mai

${ }^{3}$ Trung tâm Bênh nhiết đới, Bênh viên Bach Mai

Chịu trách nhiệm chính: Ngô Thị Thanh Loan

Email: bsngoloan@gmail.com

Ngày nhận bài: 12.8.2021

Ngày phản biên khoa hoc: 8.10 .2021

Ngày duyệt bài: 12.10 .2021
Ngô Thi Thanh Loan', Phạm Thị Hồng Thi², Đố Duy Cường ${ }^{3}$, Nguyễn Thị Thu Hoài ${ }^{2}$

Child - Pugh $C(p<0.001)$, sự xuất hiện cổ trướng $(\mathrm{p}<0.001)$ và INR $\geq 1.3(\mathrm{p}=0.001)$ là những yếu tố có ý nghĩa dự báo khả năng bị rối loạn CNTTr ở bệnh nhân xớ gàn do HBV.

Tư khóa: Xơ gan; chức năng tâm trương thất trái.

\section{SUMMARY}

\section{LEFT VENTRICULAR DIASTOLIC}

DYSFUNCTION IN PATIENTS WITH

HEPATITIS B VIRUS-RELATED CIRRHOSIS

Objjectives: Study of left ventricular diastolic function by echocardiography in patients with hepatitis $B$ virus-related cirrhosis. Patients and methods: Cross-sectional descriptive study was carried out on 68 HBV related cirrhotic patients and 30 matched subjects without a previous history of cardiac in Bach Mai Hospital from July 2020 to August 2021. All study participants underwent cardiac assessment with echocardiography, the parameters assessed included annular $\mathrm{e}^{\prime}$ velocity (septal $\mathrm{e}^{\prime}$, ateral $\mathrm{e}^{\prime}$ ), average $\mathrm{E} / \mathrm{e}^{\prime}$ ratio, LA maximum volume index (LAVi $\mathrm{ml} / \mathrm{m}^{2}$ ), and peak TR velocity (TRV m/s). Results: Annular $\mathrm{e}^{\prime}$ velocity was lower, average $\mathrm{E} / \mathrm{e}^{\prime}$ ratio was higher, LAVi and TRV were higher in the HBV related cirrhotic group $(p<0.01) .48 .5 \%$ of patients with HBV related 
cirrhosis had diastolic dysfunction. Child - Pugh grade C $(p<0.001)$, ascites $(p<0.001)$ and INR $\geq 1.3$ $(p=0.001)$ were significant predictors of diastolic dysfunction in patients with hepatitis $B$ virus-related cirrhosis.

Key words: Cirrhosis; left ventricular diastolic dysfunction.

\section{I. ĐĂT VẤN ĐỀ}

Nhiễm virus viêm gan $B$ (HBV) là nguyên nhân phổ biến nhất gây xơ gan ở khu vực châu Á - Thái Bình Dương. Việt Nam thuộc vùng dịch tễ lưu hành cao nhiểm HBV với tỷ lệ $10-20 \%^{1}$ và tỷ lệ xơ gan do HBV chiếm khoảng $50 \%$ số trường hợp xơ gan. ${ }^{2}$

Bệnh cơ tim do xơ gan (CCM) là một trong những biến chứng của xơ gan, lần đầu tiền được xác định vào năm 2005 tại Đại hội tiêu hóa thế giới. CCM được định nghĩa theo các tiêu chuẩn lâm sàng sau: (1) không có bệnh tim khác đã biết trước khi được chẩn đoán suy gan, (2) rối loạn chức năng tâm thu thất trái, (3) rối loạn CNTTr thất trái, (4) bất thường điện sinh lý. ${ }^{3}$

Rối loạn CNTTr trong suy gan đã được quan sát thây trong nhiều NC trên thế giới. Các NC cho thấy mức độ của CCM có xu hướng xấu đi cùng với mức độ tiến triển của xơ gan. ${ }^{4}$ Các $B N$ xơ gan thường có những thay đổi đáng kể về mức đổ đầy tâm trương. Rối loạn CNTTr trong bệnh gan mãn tính có thể được chứng minh khi không có tăng huyết áp, động mạch vành hoặc bệnh van tim. Điều này có thể liên quan đến tốc độ giải phóng canxi từ troponin, và tốc độ nó quay trở lại lưới bào tương. Compliance tâm trương có thể được đo bằng siêu âm tim qua lồng ngực, và các bất thường thường xuất hiện trước khi quan sát thấy những thay đổi của chức năng tâm thu.

Hiện nay ở Việt Nam, những ảnh hưởng của xơ gan do HBV lên hệ tim mạch chưa thực sự được hiểu và quan tâm NC. Vì vậy, chúng tối tiến hành NC này nhằm đánh giá CNTTr thất trái trên siêu âm tim ở BN xơ gan do HBV.

\section{II. ĐỐI TƯỢNG VÀ PHƯƠNG PHÁP NGHIÊN CỨU \\ Đối tượng nghiên cứu: NC được tiễn hành} trên 68 BN xơ gan do HBV (nhóm bệnh) ở giai đoạn Child - Pugh $B, C$ và 30 người khỏe mạnh (nhóm chứng) điều trị tại Trung tâm Bệnh nhiệt đới và Viện tim mạch Bệnh viện Bạch Mai từ tháng 7/2020 đến tháng 8/2021.

- Nhóm bệnh: Chẩn đoán xớ gan do HBV chủ yếu dựa theo các tiêu chuẩn của Tổ chức y tế Thế giới (WHO) $2015^{5}$ và Hội gan mật Châu Á -
Thái Bình Dương (APASL) năm 2016². BN đồng ý tham gia nghiên cứu.

Loại khỏi nhóm NC những trường hợp xơ gan do HBV có Hemoglobin $\leq 90 \mathrm{~g} / \mathrm{l}$, kèm theo ung thư biểu mô tế bào gan, đồng dương tính với HCV, HDV, HAV, HEV, HIV, có huyết khối tĩnh mạch cửa, đang có biến chứng nặng như xuất huyết tiêu hóa, đang sử dung một số thuốc ảnh hưởng đến chức năng tim (như chẹn $\beta$ ), nghiện rượu hoặc có các bệnh lý nội - ngoại khoa kèm theo, xơ gan Child - Pugh A.

- Nhóm chứng: Không có bệnh lý nội - ngoại khoa và đồng ý tham gia nghiên cứu

Phương pháp nghiên cứu: Nghiên cứu mô tả, cắt ngang.

Tất cả BN nghiên cứu được hỏi tiền sử, khám lâm sàng và chỉ định làm xét nghiệm cần thiết để xác định hội chức suy chức năng gan và tăng áp lực tĩnh mach cửa, có căn nguyên do HBV. Phân loại mức độ xơ gan theo thang điểm của Child Pugh. BN được làm siêu âm tim trên cùng hệ thống máy siểu âm tim Vivid E95 (GE) với đầu dò ma trân 2D M5Sc-D, cho phép tính toán các thông số đánh giá chức năng tim và các thông số Doppler một cách tự động. Tất cả các đối tượng nghiên cứu đều được thực hiện siêu âm bởi cùng một bác sĩ chuyên về siêu âm tim.

Đánh giá CNTTr thất trái: Sử dụng siêu âm doppler dòng chảy qua van hai lá kết hợp với siêu âm Doppler mô vòng van hai lá. Bốn thông số được khuyến cáo đánh giá CNTTr thất trái là vận tốc e'vòng van hai lá ( $\mathrm{e}^{\prime}$ vách, $\mathrm{e}^{\prime}$ bên), tỷ lê $\mathrm{E} / \mathrm{e}^{\prime} \mathrm{TB}$, chỉ số thể tích nhĩ trái tối đa (LAVI $\mathrm{ml} / \mathrm{m}^{2}$ ), và vận tốc tối đa dòng hở van ba lá (TRV $\mathrm{m} / \mathrm{s}$ ). Các sổ liệu được thu thâp theo mẫu bênh án nghiên cứu và xử lý số liệu bằng phần mềm SPSS 16.0 .

\section{KẾT QUẢ NGHIÊN CỨU}

Đặc điểm chung của nhóm nghiên cứu. Trong thời gian từ tháng $7 / 2020$ đến tháng $8 / 2021$ chúng tôi đã NC trên 68 BN Xơ gan do HBV so với 30 đối tượng ở nhóm chứng, thấy không có sự khác biệt đáng kể về tỷ lệ nam/ nữ (54/14 so với $21 / 9, p=0.31$ ) và tuổi trung bình (47.40 \pm 11.34 so với $47.30 \pm 13.08, p=0.97)$. Trong nhóm BN xơ gan do HBV, $47.1 \%$ (32 BN) ở giai đoạn Child - Pugh B, 52.9\% (36 BN) ở giai đoạn Child - Pugh C; có 58.8\% tương đương 40 $\mathrm{BN}$ có cổ trướng.

Đặc điểm chức năng tâm trương thất trái ở bệnh nhân xơ gan do HBV

\section{Bảng 1. Chức năng tâm trương thât trái ở 2 nhóm nghiên cứu}


VIETNAM MEDICAL JOURNAL N²2 - NOVEMBER - 2021

\begin{tabular}{|c|c|c|c|}
\hline Chỉ số & Nhóm chứng(n=30) $\bar{x}_{ \pm S D}$ & Nhóm xơ gan do HBV $(n=68)^{x} \pm S D$ & $\mathbf{p}$ \\
\hline $\mathrm{E}(\mathrm{cm} / \mathrm{s})$ & $70.91 \pm 6.47$ & $80.53 \pm 12.91$ & $<0.001$ \\
\hline $\mathrm{A}(\mathrm{cm} / \mathrm{s})$ & $62.39 \pm 6.16$ & $82.14 \pm 16.74$ & $<0.001$ \\
\hline Tỷ lệ E/A & $1.14 \pm 0.13$ & $1.02 \pm 0.27$ & 0.009 \\
\hline $\mathrm{e}^{\prime}$ vách $(\mathrm{cm} / \mathrm{s})$ & $10.07 \pm 2.58$ & $7.3 \pm 1.52$ & $<0.001$ \\
\hline $\mathrm{e}^{\prime}$ bên $(\mathrm{cm} / \mathrm{s})$ & $11.82 \pm 2.65$ & $9.59 \pm 2.37$ & 0.001 \\
\hline Tỷ lệ E/e'TB & $6.70 \pm 1.58$ & $9.92 \pm 2.59$ & $<0.001$ \\
\hline TRV $(\mathrm{m} / \mathrm{s})$ & $1.97 \pm 0.28$ & $2.26 \pm 0.41$ & 0.002 \\
\hline LAVi $\left(\mathrm{ml} / \mathrm{m}^{2}\right)$ & $20.29 \pm 5.45$ & $27.69 \pm 6.30$ & $<0.001$ \\
\hline
\end{tabular}

Ơ $B N$ Xơ gan do $H B V$, vận tốc tối đa sóng $E$ và sóng $A$ tăng, tỷ lệ $E / A$ giảm, vận tốc $e^{\prime}$ vách giảm, $e^{\prime}$ thành bên giảm, tỷ lệ $E / e^{\prime}$ TB tăng, TRV tăng, LAVi tăng khi so sánh với nhóm chứng với $p<0.01$.

\section{Bảng 2. Ti lệ suy CNTTr thất trái ở bệnh nhân xơ gan do HBV}

\begin{tabular}{|c|c|c|c|}
\hline \multicolumn{2}{|c|}{ CNTTr } & Số lượng & Tỷ lệ \% \\
\hline \multirow{2}{*}{$\begin{array}{c}\text { Rối loạn CNTTr } \\
\text { (n=68) }\end{array}$} & Không & 35 & 51.5 \\
\cline { 2 - 4 } & Có & 33 & 48.5 \\
\hline \multirow{2}{*}{$\begin{array}{c}\text { Mức độ rối loạn } \\
\text { CNịTr }\end{array}$} & Độ 1 & 18 & 26.5 \\
\cline { 2 - 4 } & Độ 2 & 15 & 22.0 \\
\cline { 2 - 4 } & Độ 3 & 0 & 0 \\
\hline
\end{tabular}

48.5\% số BN xơ gan do HBV trong nghiên cứu có tình trang rối loạn CNTTr, trong đó chủ yếu là rối loạn CNTTr độ 1 và độ 2 (chiếm $26.5 \%$ và $22.0 \%$ theo thứ tự), không có BN rối loạn CNTTr độ 3.

Bàng 3. CNiTr thất trái theo giai đoạn xơ gan do HBV

\begin{tabular}{|c|c|c|c|}
\hline \multirow[b]{2}{*}{ Chỉ số } & \multicolumn{2}{|c|}{ Giai đoạn xơ gan do HBV $\bar{\tau}$} & \multirow[b]{2}{*}{$\mathbf{p}$} \\
\hline & Child - Pugh B $(n=32)^{x} \pm$ SD & Child - Pugh C $(n=36)^{x} \pm$ SD & \\
\hline $\mathrm{E}(\mathrm{cm} / \mathrm{s})$ & $79.18 \pm 12.95$ & $81.74 \pm 12.94$ & 0.42 \\
\hline $\mathrm{A}(\mathrm{cm} / \mathrm{s})$ & $75.23 \pm 15.17$ & $88.23 \pm 15.85$ & 0.004 \\
\hline Tỷ lệ E/A & $1.10 \pm 0.30$ & $0.95 \pm 0.22$ & 0.04 \\
\hline e'vách $(\mathrm{cm} / \mathrm{s})$ & $7.94 \pm 1.48$ & $6.73 \pm 1.34$ & $<0.001$ \\
\hline e'bên $(\mathrm{cm} / \mathrm{s})$ & $10.24 \pm 2.25$ & $9.02 \pm 2.35$ & 0.04 \\
\hline Tý lệ E/e'TB & $8.94 \pm 1.83$ & $10.79 \pm 2.87$ & 0.008 \\
\hline TRV $(\mathrm{m} / \mathrm{s})$ & $2.10 \pm 0.32$ & $2.41 \pm 0.43$ & 0.001 \\
\hline $\operatorname{LAVi}\left(\mathrm{ml} / \mathrm{m}^{2}\right)$ & $26.12 \pm 5.88$ & $29.08 \pm 6.41$ & 0.05 \\
\hline
\end{tabular}

Ớ nhóm xơ gan Child Pugh $C$ tăng vận tốc sóng $A$, giảm tỷ lệ $E / A$, giảm vận tốc $e^{\prime}$, tăng tỷ lệ $E / e^{\prime} T B$, tăng TRV so với nhóm xơ gan Child - Pugh $B, p<0.05$.

Báng 4. Hồi quy logistic đớn biến môi tương quan giứa rôi loạn CNTTr thất trái với chỉ số đánh giá chức năng gan, mức độ xơ gan và cô trướng

\begin{tabular}{|c|c|c|c|c|}
\hline Các yếu tố & So sánh & OR & $95 \% \mathrm{CI}$ & $\mathbf{P}$ \\
\hline $\begin{array}{c}\text { Mức độ xớ gan Child - } \\
\text { Pugh }\end{array}$ & $\begin{array}{l}\mathrm{B} \\
\mathrm{C}\end{array}$ & $\begin{array}{c}1 \\
6.82 \\
\end{array}$ & $2.34-19.86$ & $<0.001$ \\
\hline Cổ trướng & $\begin{array}{l}\text { Không } \\
\text { Có }\end{array}$ & $\begin{array}{c}1 \\
7.62\end{array}$ & $2.49-23.32$ & $<0.001$ \\
\hline Tiểu câu (G/I) & $\begin{array}{l}\geq 100 \\
<100\end{array}$ & $\begin{array}{c}1 \\
1.25\end{array}$ & $0.46-3.34$ & 0.66 \\
\hline Albumin $(\mathrm{g} / \mathrm{l})$ & $\begin{array}{l}\geq 35 \\
<35\end{array}$ & $\frac{1}{4.00}$ & $0.99-16.14$ & 0.05 \\
\hline Bilirubin TP $(\mu \mathrm{mol} / \mathrm{l})$ & $\begin{array}{l}<35 \\
\geq 35\end{array}$ & $\begin{array}{c}1 \\
1.62\end{array}$ & $0.48-5.71$ & 0.42 \\
\hline INR & $\begin{array}{l}<1.3 \\
\geq 1.3\end{array}$ & $\frac{1}{16.41}$ & $3.39-79.37$ & 0.001 \\
\hline
\end{tabular}

Có $3 / 6$ yễu tố liên quan có ý nghĩa dự báo khả năng bị rối loạn CNTTr bao gồm mức độ Child Pugh, sự xuất hiện cổ trướng, và INR $\geq 1.3$.

Bảng 5. Hồi quy logistic đa biến môi tương quan giữa rôi loạn CNTTr thất trái với chỉ số đánh giá chức năng gan, mức độ xớ gan và cố trướng

đánh giá chức năng gan, mức độ xơ gan và cố trướng
\begin{tabular}{|c|c|c|c|c|}
\hline Các yếu tố & So sánh & OR & $\mathbf{9 5 \% C I}$ & P \\
\hline Mức độ xơ gan Child - & B & 1 & $0.10-5.82$ & 0.81 \\
\cline { 2 - 5 } Pugh & C & 0.78 & $1.62-112.63$ & 0.016 \\
\hline Cố trướng & Không & 1 & \\
\hline
\end{tabular}




\begin{tabular}{|c|c|c|c|c|}
\hline & Có & 13.49 & & \\
\hline \multirow{2}{*}{ INR } & $<1.3$ & 1 & \multirow{2}{*}{$3.95-168.85$} & 0.001 \\
\cline { 2 - 3 } & $\geq 1.3$ & 25.82 & \\
\hline
\end{tabular}

Phân tích hồi quy logistic đa biến đồng thời các yếu tố ban đầu liên quan đến khả năng bị rối loạn CNTTr thất trái có giá trị $p<0,05$. Sự xuất hiện cố trướng và INR $\geq 1.3$ là những yếu tố độc lập dự báo khả năng rối loạn CNTTr thất trái.

\section{BÀN LUÂ̂N}

Ở BN xơ gan do HBV rối loạn CNTTr thất trái có thể dễ dàng thấy trên siêu ẩm tim khi nghỉ. Ở NC này, chúng tôi đánh giá CNTTr thất trái theo khuyến cáo của ASE $2016^{7}$ và Hiêp hội CCM $2019^{3}$ gồm bốn thông số đánh giá rối loạn CNTTr và điểm cắt giá trị bất thường là vận tốc $\mathrm{e}^{\prime}$ vòng van hai lá bằng Doppler mô ( $\mathrm{e}^{\prime}$ vách $<7 \mathrm{~cm} / \mathrm{s}$. e'bên $<10 \mathrm{~cm} / \mathrm{s}$ ), tỷ lệ $E / \mathrm{e}^{\prime}$ trung bình $>14$, chỉ số thể tích nhĩ trái (LAVi) $>34 \mathrm{ml} / \mathrm{m}^{2}$ và vận tốc tối đa dòng hở van ba lá (TRV) $>2.8 \mathrm{~m} / \mathrm{s}$, để giảm chẩn đoán dương tính giả rôi loạn CNTTr.

Kết quả nghiên cứu của chúng tôi trình bày ở bảng 1 cho thấy BN xơ gan do HBV có giảm vận tốc $\mathrm{e}^{\prime}$ vách, giảm vận tốc $\mathrm{e}^{\prime}$ bên, tăng tỷ lệ $\mathrm{E} / \mathrm{e}^{\prime}$ trung bình, tăng TRV, tăng LAVi so với nhóm chứng, $\mathrm{p}<0.01$. Ngoài ra, ở $\mathrm{BN}$ xơ gan do HBV thấy tăng vận tốc sóng $E$ và $A$, giảm tỷ lệ $E / A$ so với nhóm chứng, $\mathrm{p}<0.01$.

Sử dụng tiêu chuẩn phân loại rối loạn CNTTr thất trái của Hiệp hội CCM $2019^{3}$, chúng tôi ghi nhận $48.5 \%$ BN xớ gan do HBV có rối loạn CNTTr, trong đó rối loạn CNTTr độ 1 chiểm $26.5 \%$, rối loạn CNTTr độ 2 chiếm $22.0 \%$, không có BN rối loạn CNTTr độ 3. Yuan W và CS (2019) nghiên cứu trên 79 BN xơ gan do HBV, nhận thây $48.10 \%$ số BN có rối loạn CNTTr. Siêu âm Doppler mô vòng van hai lá trong đánh giá CNTTr thất trái hạn chế tối đa ảnh hưởng của tiền gánh và do đó có thể thu được kêt quả chính xác hơn. ${ }^{8}$

So sánh CNTTr thất trái giữa 2 nhóm xơ gan Child - Pugh $B$ và Child - Pugh $C$ chúng tôi thu được kết quả: ở nhóm xơ gan Child - Pugh $C$ thấy tăng vận tốc sóng $A$, giảm tỷ lệ $E / A$, giảm vận tốc $e^{\prime}$, tăng tỷ lệ $E / e^{\prime}$ trung bình, tăng TRV có ý nghĩa thống kê so với nhóm xơ gan Child Pugh $B, p<0.05$.

Mối liên quan giữa CNTTr thất trái theo mức độ xơ gan do HBV và sự xuất hiện cổ trướng được thể hiện ở bảng 4, bảng 5 . Khi phân tích hồi quy logistic đơn biến chúng tôi ghi nhận có $3 / 6$ yêu tố liên quan có ý nghĩa thống kê dự báo khả năng rối loạn CNTTr thất trái, bao gồm Child - Pugh $C(p<0.001)$, có cổ trướng $(p<0.001)$ và INR $\geq 1.3 \quad(p=0.001)$. Khi phân tích hồi quy Logistic đa biến đồng thời 3 yếu tố trên, sự xuất hiện cổ trướng và INR $\geq 1.3$ là những yếu tố độc lập dự báo khả năng rối loạn CNTTr thất trái.

INR là một chỉ điểm phản ánh chức năng đông máu. Xơ gan sẽ làm giảm tổng hợp các yếu tố đông máu, thời gian đông máu càng kéo dài chứng tỏ mức độ suy gan càng nặng. INR cũng là tham số ảnh hưởng nhiều nhất đến tính điểm MELD để ưu tiên bệnh nhân ghép gan. Chức năng gan thoái triển càng nặng sẽ gia tăng tình trạng cũng như mức độ rối loạn CNTTr, từ đó làm tăng nguy cơ tử vong đặc biết nếu bệnh nhân được thực hiện các kỹ thuật điều trị như tạo shunt cửa chủ trong gan hoăc ghép gan. Ở BN xơ gan khi xuất hiện cổ trướng thì rối loạn chức năng tim nhất là rối loạn CNTTr thất trái sẽ trở nên nặng nề hơn so với khi chưa có cổ trướng. Cơ chế của hiện tượng này là cổ trướng đẩy vòm hoành lên cao, làm tăng áp lực trong lồng ngực, từ đó gây hạn chế quá trình giãn nở thất để nhận máu có hiệu quả.

\section{KẾT LUẬN}

- Rối loạn CNTTr thất trái ở BN xơ gan do HBV thể hiện vận tốc e' vách, e' bên giảm, tỷ lệ E/e'TB tăng, TRV tăng, LAVi tăng khi so sánh với nhóm chứng, $\mathrm{p}<0.01 ; 48.5 \%$ BN xơ gan do HBV có rối loạn CNTTr thất trái, trong đó rối loạn CNTTr độ 1 là $26.5 \%$, độ 2 là $22 \%$ và không có rối loạn CNTTr độ 3.

- Mức độ Child - Pugh $C(p<0.001)$, sự xuất hiện cổ trướng $(p<0.001)$ và INR $\geq 1.3$ $(p=0.001)$ là những yếu tố có ý nghĩa dự báo khả năng bị rối loạn CNTTr ở bệnh nhân xớ gan do HBV. Khi phân tích hồi quy logistic đa biến, sự xuất hiện cổ trướng và INR $\geq 1.3$ là yếu tố độc lập dự báo khả năng rối loạn CNTTr ở bệnh xơ gan do HBV.

\section{TÀI LIỆU THAM KHẢO}

1. Nguyen VTT (2012). Hepatts $B$ infecton in Vietnam: Current Issues and Future Challenges. AsiaPacifc Journal of Public Health; 24(2): 361-373.

2. Trân Văn Huyy, Nguyê̂n Thị Huyền Thương (2016). Nghiên cưư hiệu quả của tenofovir trên bệnh nhân xơ gan do virus viêm gan $B$. Tạp chí Y Dược học - Trường Đại học Y Dược Huế; 32: 25-29.

3. Izzy M, VanWagner LB, Lin G, et al. Redefining Cirrhotic Cardiomyopathy for the Modern Era. Hepatology; 2020 Jan;71(1):334-45

4. Lee RF, Glenn TK, Lee SS. Cardiac dysfunction in cirrhosis. Best Pract Res Clin Gastroenterol. 2007; 21(1): $125-40$. 
5. World Health Organization (2015). Guidelines for the Prevention, Care and Treatment of Persons with Chronic Hepatitis B Infection. Pp. 1-166.

6. Sarin, S. K., Kumar, M., Lau, et al (2016). Asian-Pacific clinical practice guidelines on the management of hepatitis B: a 2015 update. Hepatology international, 10(1), 1-98. https://doi.org/10.1007/s12072-015-9675-4

7. Nagueh SF, Smiseth OA, Appleton CP, et al. Recommendations for the Evaluation of Left
Ventricular Diastolic Function by Echocardiography: An Update from the American Society of Echocardiography and the European Association of Cardiovascular Imaging. J Am Soc Echocardiogr. 2016; 29:277-314.

8. Yuan W., Lu, H. Z., Mei, X., et al (2019). Cardiac health in patients with hepatitis B virusrelated cirrhosis. Medicine; 98(13), e14961. https://doi.org/10.1097/MD.0000000000014961

\section{HIÊUU QUẢ PHỐI HỢP KHÁNG SINH IN VITRO TRÊN VI KHUẨN GRAM ÂM KHÁNG CARBAPENEM}

\begin{abstract}
TÓM TẮT.
Đă̆t vấn đề: Theo Tổ chức $Y$ tế thế giới (WHO), vi khuẩn (VK) Acinetobacter baumannii, Pseudomonas aeruginosa, Klebsiella pneumoniae kháng carbapenem (APK-CR) là những vi khuẩn (VK) có mức cảnh báo cao nhất, cần ưu tiên phát triển các loại kháng sinh (KS) mới do tình trạng kháng thuốc đáng báo động [7]. Mục tiêu: Khảo sát MIC và hiệu quả phối hợp KS in vitro của meropenem (ME) - colistin (COL) và meropenem - ciprofloxacin (CIP) trên các chủng VK APK-CR. Phương pháp: Nghiên cứu mô tả cắt ngang. Các chủng APK-CR được phân lập tai Bênh viện Đại học Y Dược TP. HCM từ tháng 12/2020 đến tháng 06/2021. Kết quả: Có 151 chủng gồm 51 chủng $A$. baumannii, 50 chủng $P$. aeruginosa và 50 chủng $K$. pneumoniae. MIC của ME và CIP trên các chủng APKCR đều cao (chiếm 92-100\%); có $6 \%$ chủng $P$. aeruginosa và $10 \%$ chủng $\mathrm{K}$. pneumoniae là có MIC kháng COL. Hiệu quả hiệp đồng và cộng hợp trong phối hợp KS in vitro của ME-COL trên APK-CR có tỷ lệ lần lượt là $58,8 \%$ và $41,2 \%, 32 \%$ và $60 \%, 20 \%$ và $60 \%$. Hiệu quả hiệp đồng và cộng hợp trong phối hợp $\mathrm{KS}$ in vitro của ME-CIP trên APK-CR có tỷ lệ lần lượt là $33,3 \%$ và $45,1 \%, 30 \%$ và $60 \%, 42 \%$ và $44 \%$. Kết luâan: $A P K-C R$ đề kháng với $M E$, CIP với tỷ lê rất cao. Phối hợp ME-COL và ME-CIP trên APK-CR có kết quả hiệp đồng và cộng hợp làm giảm tỷ lệ đề kháng KS của APK-CR.
\end{abstract}

Từ khoá: phối hợp kháng sinh, APK-CR (A. baumannii - P.aeruginosa - K.pneumoniae kháng carbapenem).

\section{SUMMARY}

\section{IN-VITRO EFFICACY OF ANTIBIOTIC}

${ }^{1}$ Trường Đại học Y Khoa Phạm Ngọc Thạch

${ }^{2} Đ a ̣ i$ học Y Dước TPHCM

${ }^{3}$ Bềnh viên Đai hoc Y Dước TPHCM

Chịu trách nhiệm chính: Ngô Hoàng Ngọc Thanh

Email: hoang.nthanh71@gmail.com

Ngày nhận bài: 16.10 .2021

Ngày phản biên khoa hoc: 11.10.2021

Ngày duyệt bài: 18.10.2021
Ngô Hoàng Ngọc Thanh ${ }^{1}$, Phạm Thái Bình²,
Cao Minh Nga

\section{COMBINATION ON THE CARBAPENEM-}

RESISTANT GRAM-NEGATIVE BACTERIA

Background: According to the World Health Organization, Acinetobacter baumannii, Pseudomonas aeruginosa, and Klebsiella pneumoniae carbapenem resistance (APK-CR) are the most dangerous bacteria. The new antibiotic development should be prioritized for APK-CR because of their antibiotic resistance seriously. Objective: Evaluate the resistance of APK and the effectiveness of in vitro antibiotic combination of meropenem (ME) - colistin (COL) and meropenem ciprofloxacin (CIP) to these bacteria strains. Methods: Descriptive and analytical cross sectional study. APK-CR strains were collected at University Medical Center in Ho Chi Minh City from December 2020 to June 2021. Results: There were 151 APK-CR strains (51 A. baumannii, $50 \mathrm{P}$. aeruginosa and $50 \mathrm{~K}$. pneumoniae). The MICs of ME and CIP on APK-CR strains were both high (accounting for $92-100 \%$ ); $6 \%$ of $\mathrm{P}$. aeruginosa and $10 \%$ of $\mathrm{K}$. pneumoniae were MIC resistant to $\mathrm{COL}$. The combination of ME-COL gave high synergistic and additive effectiveness on $A$. baumannii at the rate of $58.8 \%$ and $41.2 \%$, while $P$. aeruginosa showed the lower rate of $32 \%$ and $60 \%$, K. pneumoniae was at the rate of $20 \%$ and $60 \%$. The combination of ME-CIP gave high synergistic and additive effectiveness on $\mathrm{K}$. pneumoniae at the rate of $42 \%$ and $44 \%$, while A. baumannii showed the lower rate of $33.3 \%$ and $45.1 \%$, P. aeruginosa was at the rate of $30 \%$ and $60 \%$. Conclusion: APK-CR resists to $\mathrm{ME}$ and CIP with a very high rate. The antibiotic combination in vitro of ME-COL and ME-CIP on APK-CR has the synergistic and additive effectiveness.

Key words: combination antibiotic, APK-CR (A. baumannii - P. aeruginosa - K. pneumoniae carbapenem resistance).

\section{I. ĐĂTT VẤN ĐỀ}

Theo Cơ quan Quản lý Dược phẩm Châu Âu, mỗi năm có 33.000 ca tử vong do nhiễm VK đa kháng thuốc và chi phí lên đến 1,5 tỷ Euro mỗi năm [5]. WHO đưa ra danh sách các VK cần ưu tiên phát triển KS mới do tình trạng kháng thuốc 